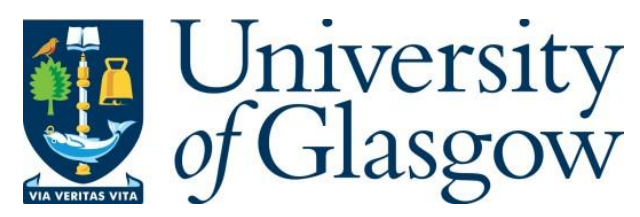

Danjuma, I. M., Akinsolu, M. O., See, C. H., Abd-Alhameed, R. and Liu, B. (2020) Design and optimization of a slotted monopole antenna for ultra-wide band body centric imaging applications. IEEE Journal of Electromagnetics, RF and Microwaves in Medicine and Biology, 4(2), pp. 140-147.

There may be differences between this version and the published version. You are advised to consult the publisher's version if you wish to cite from it.

http://eprints.gla.ac.uk/213466/

Deposited on: 7 April 2020

Enlighten - Research publications by members of the University of Glasgow http://eprints.gla.ac.uk 


\section{Design and Optimization of a Slotted Monopole Antenna for Ultra-Wide Band Body Centric Imaging Applications}

Isah M. Danjuma, Member, IEEE, Mobayode O. Akinsolu, Member, IEEE, Chan H. See, Senior Member, IEEE, Raed A. Abd-Alhameed, Senior Member, IEEE, and Bo Liu, Senior Member, IEEE.

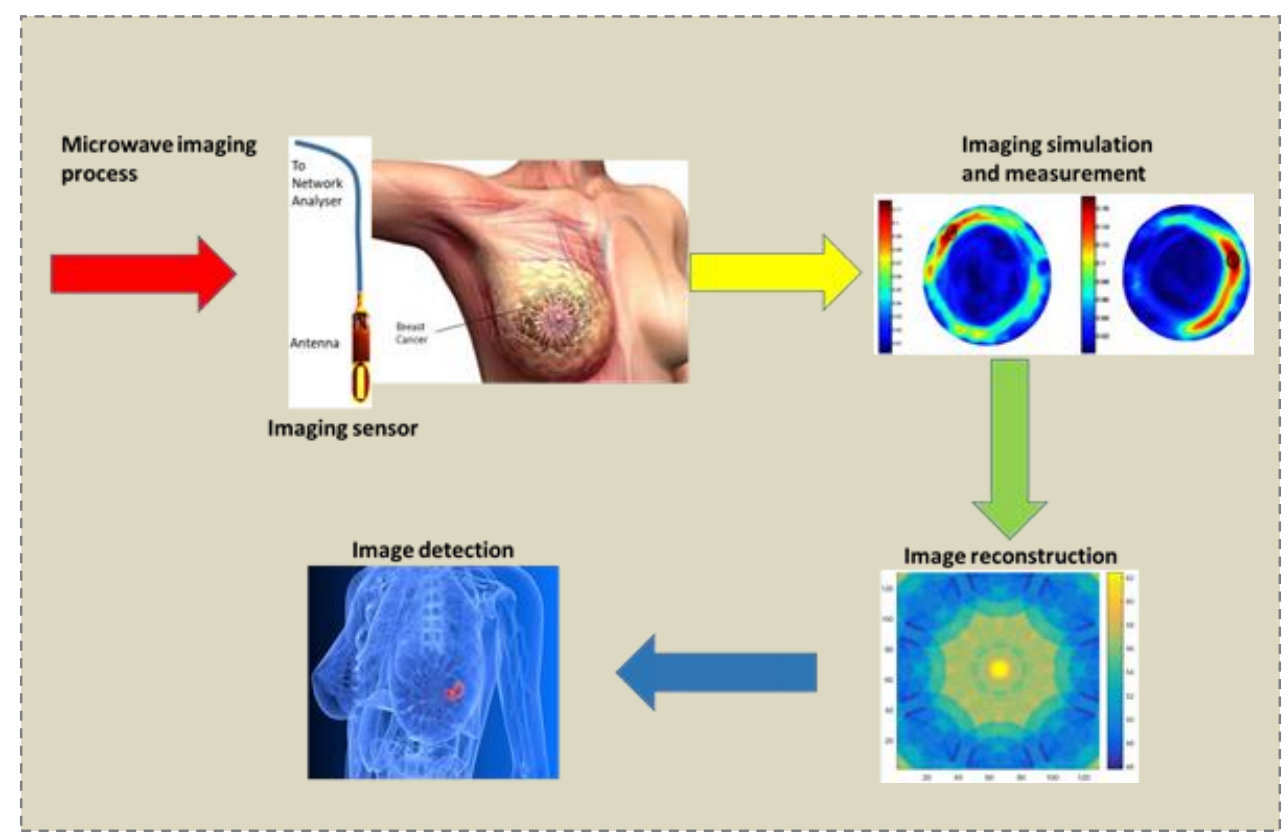

Breast Cancer early detection by the use of microwave imaging and image reconstruction algorithm.

Take-Home Messages

- Microwave imaging provide an in expensive, non-ionizing and nondestructive evaluation of the cell tissues for clinical analysis and medical diagnosis.

- We demonstrate that the antenna performs well even in close proximity to the phantoms and operationally covers the Federal Communications Commission (FCC) range of the Ultra-Wide Band (UWB) spectrum.

- Our target application is centered on the detection of breast cancer at early stage, which serve as a key factor in the successful treatment of the disease.

- This work has demonstrated the use of Parallel Surrogate Assistance Differential Evolution Algorithm (PSADEA) optimisation technique in reducing the size of the antennas considerably.

- The optimization techniques used in this our work provide the sensor with a good return loss in the UWB frequencies of 3.1 to $10.6 \mathrm{GHz}$ and maintains its bandwidth UWB operation without detuning when placed in closed contact with the human body or breast mimicking tissue (phantom). 


\title{
Design and Optimization of a Slotted Monopole Antenna for Ultra-Wide Band Body Centric Imaging Applications
}

\author{
Isah M. Danjuma, Member, IEEE, Mobayode O. Akinsolu, Member, IEEE, Chan H. See, Senior \\ Member, IEEE, Raed A. Abd-Alhameed, Senior Member, IEEE, and Bo Liu, Senior Member, IEEE.
}

\begin{abstract}
This paper presents a cost-efficient design, optimization and physical implementation of a compact slotted ultrawideband (UWB) monopole antenna for body-centric imaging applications. The proposed antenna is initially modelled and designed with the aid of commercial software (CST-Microwave Studio). To ensure that the proposed design is meeting the required specifications with reduced design time, the parallel surrogate model-assisted hybrid differential evolution for antenna optimization (PSADEA) is proposed to optimize the design. Based on the best set of geometry parameters for the optimum antenna performance, the antenna prototype is realized on an FR-4 substrate and analyzed in terms of bandwidth, gain, efficiency, and radiation pattern with and without the tissue models. All measured results are found to be in good agreement with the simulated results. The antenna provides a good reflection coefficient $\left(\mathrm{S}_{11}<-10 \mathrm{~dB}\right)$ in the UWB frequency band from $3.1 \mathrm{GHz}$ to $10.6 \mathrm{GHz}$ and maintains its bandwidth UWB operation without detuning when placed in closed contact with the human body or breast mimicking tissues (phantoms).
\end{abstract}

Keywords - Antenna Optimization, Body-centric communications, Breast cancer detection, Monopole Antennas, UWB Antennas.

\section{INTRODUCTION}

$\mathrm{T}$ HE emergence of the Internet of Things (IoT) for smart cities has triggered the unabated demand of using the new unlicensed ultra-wideband (UWB) spectrum covering from 3.1 - $10.6 \mathrm{GHz}$ which was released by the Federal Communications Commission (FCC) in the US in February 2002 [1]. This has led to numerous UWB technology applications in the area of through the wall, ground-penetrating radar imaging [2]. Others are breast cancer, brain imaging, and body-centric wireless communications [3-5].

Body centric wireless communications have enormous applications in military, space exploration, identification systems, breast cancer detection, personal health care systems, smartphones, and personal entertainment systems [6].

Manuscript submitted November 15, 2019. This work has partially been supported by the European Union's Horizon 2020 Research and Innovation programme under grant agreement H2020-MSCA-RISE-2019-eBORDER872878 .

This paper is expanded from a presentation at the 2019 IEEE International Symposium on Antennas and propagation and USNC-URSI Radio Science Meeting held in Atlanta, GA, USA.

Isah. M. Danjuma and Raed. A. Abd-Alhameed are with the School of Engineering and Informatics, University of Bradford, BD7 1DP, U.K (e-mail: i.m.danjuma@bradford.ac.uk).

Mobayode. O. Akinsolu is with the Faculty of Arts, Science, and Technology, Wrexham Glyndŵr University, LL11 2AW, U.K. (e-mail: M.O. Akinsolu@ ieee.org).

B. Liu is with the James Watt School of Engineering, University of Glasgow, G12 8QQ, U.K., and the School of Electrical, Electronic, and System Engineering, University of Birmingham, B15 2TT, U.K. (e-mail: liubo168@gmail.com,

C. H. See is with School of Engineering \& the Built Environment, Edinburgh Napier University, EH11 4BN (e-mail: C.See@ napier.ac.uk).

Corresponding authors: R. Abd-Alhameed (antenna); B. Liu ((AI-driven antenna design algorithm)
These systems require antenna elements to communicate in body centric sensing systems, usually formed by parts of wireless communications combining the network of Wireless Sensor Networks (WSNs), Wireless Body-Area Networks (WBANs), and Wireless Personal Area Networks (WPANs) in the off, in-body, and on-body wireless communications. Due to having large bandwidth, low cost, high data rate, high resolution, and high resistance to interference, reasonable gain, and low power requirement, UWB antennas are more attractive than the narrow band antennas for body-centric applications [7].

These promising characteristics enable UWB antennas to possess a low probability of detection, have high resilience to fading and guarantees the signal robustness for data transmission, which is one of the key performance indicators of a body-centric wearable device that operates in a very tedious and challenging environment. However, the design of the UWB antenna could be a very challenging task as compared to narrowband antennas due to achieving more design goals of broadband operation in terms of impedance matching, group delay, fidelity factor, time domain performance and radiation characteristics [8].

Over the last decade, many UWB antennas have been proposed and studied in different body-centric wireless systems. However, due to large size geometries, high implementation cost and less compactness, some of these antennas may be unsuitable for imaging applications. In some cases, it becomes very challenging to fully characterize and integrate these antennas with the RF transceiver [9].

The performance of a body-centric UWB antenna is best evaluated when it is operating in close proximity to the body. The human body is very challenging to wireless radiation. It has been proven that the human body tissues absorb some of the power injected to the antenna, and this resulted to radiation 
pattern fragmentation, input impedance variation, and decline in radiation efficiency of the antenna which would, in turn, affect the radiation performance of the antenna $[9,10]$. Owing to the above reasons, antennas for body-centric applications are therefore required to be designed by studying the antenna in close proximity to the tissue instead of only considering the antenna in free space.

Monopole antennas are compact, simple structure, ease of fabrication and suitable for low-cost physical implementation [11]. They also offer a good radiation pattern and wide frequency impedance bandwidth [12]. These characteristics and other features make monopole antennas good candidates for body-centric imaging applications [12]. In this paper, an optimized design of a compact slotted planar monopole antenna that operates in the UWB frequency ranging from 3.1 $\mathrm{GHz}$ to $10.6 \mathrm{GHz}$ for body-centric imaging applications is proposed. In comparison to some of the published works in the literatures [12-15], as shown in Table I, the proposed antenna has a much smaller envelope size.

The parallel surrogate model-assisted differential evolution for antenna synthesis (PSADEA) method [16-18] has been employed to find the optimal design parameters, so as to satisfy the specifications. PSADEA is the state-of-the-art in the SADEA algorithm series [18-20]; which offers 3 to 20 times optimization efficiency improvement and higher optimization ability compared to several popular antenna optimizers [21, 22].

The main elements in PSADEA include Gaussian process surrogate modelling to approximate antenna performances, the complementary differential evolution search operators to find optimal antenna design, the reinforcement learning method to manage the search operators and the surrogate model-aware evolutionary search framework [23] making surrogate modeling and optimization work harmoniously.

The PSADEA optimized antenna shows satisfied characterization in terms of bandwidth, gain, efficiency and low susceptibility to fabrication tolerances. The remainder of this paper is organized as follows: section II provides the design guidelines for the proposed antenna, section III details the optimization procedure, section IV discusses the results and tests and the concluding remarks are given in section $\mathrm{V}$.

\section{Proposed Antenna Geometry And Design}

The layout of the basic design of the proposed antenna is shown in Fig. 1 and it is modelled in CST-MWS using a maximum cell density of 20 cells per wavelength (a total of about 300,000 hexahedral mesh cells). The proposed antenna is implemented on an FR-4 substrate having a thickness of 0.8 $\mathrm{mm}$, a tangential loss $(\tan \delta)$ of 0.025 and a relative permittivity $\left(\varepsilon_{r}\right)$ of 4.3 . The antenna structure consists of a driven circular patch of radius, $D P_{R}$ and four T-slots which are fused at the center of the driven circular patch to form a quasicross slot. The proposed antenna is fed by a $50 \Omega$ coaxial microstrip line with dimensions, $M_{L}$ by $M_{W}$. It has two uniforms rectangular planes with dimensions, $R P_{L}$ by $R P_{W}$, which are abreast and separated by the microstrip line. The uniform rectangular planes are both truncated and act as a coplanar partial ground. The truncation of the ground plane is primarily to enhance the input impedance and the uniform gap width, $M_{G}$ between the coplanar ground planes and the microstrip line chiefly keeping the characteristic impedance of microstrip line constant.

TABLE I

REFERENCE ANTENNAS COMPARISON WITH THE PROPOSED ANTENNA

\begin{tabular}{lc}
\hline \hline Antennas & \multicolumn{1}{c}{ Dimensions } \\
\hline$[12]$ & $0.42 \lambda_{\mathrm{o}} \times 0.27 \lambda_{\mathrm{o}} \times 0.008 \lambda_{\mathrm{o}}$ \\
{$[13]$} & $0.40 \lambda_{\mathrm{o}} \times 0.3 \lambda_{\mathrm{o}} \times 0.01 \lambda_{\mathrm{o}}$ \\
{$[14]$} & $0.55 \lambda_{\mathrm{o}} \times 0.4 \lambda_{\mathrm{o}} \times 0.016 \lambda_{\mathrm{o}}$ \\
{$[15]$} & $0.38 \lambda_{\mathrm{o}} \times 0.54 \lambda_{\mathrm{o}} \times 0.017 \lambda_{\mathrm{o}}$ \\
Proposed antenna & $0.34 \lambda_{\mathrm{o}} \times 0.15 \lambda_{\mathrm{o}} \times 0.008 \lambda_{\mathrm{o}}$ \\
\hline
\end{tabular}

where $\lambda_{\mathrm{o}}$ is the lowest operating frequency

Several techniques in the literature have been suggested and studied for the control of the surface current distribution in UWB antennas [24]. Amongst these techniques, slot etching on the radiating patch has been well demonstrated to be more effective and efficient. The slots on the radiating patch change the current path; thus, generating higher-order current modes. This development has resulted in significant changes in the antenna characteristics, which leads to a reduction in the side lobes level, gain increment, correction of the squint effect, thereby providing more improvement in the radiation characteristics.

At high frequencies on planar antennas, the current flow path tends to follow curvy paths rather than straight paths and become distributed. The current density then becomes largest on the planar surface due to skin effects. If a slot is etched on the radiating patch, by convention, the current flow will follow the curvature of the slot. As a result, the geometry of the slot affects the surface current distribution as shown in Fig. 2 for the proposed antenna. The radiation of the antenna can then be manipulated by controlling the path of the surface current [25]. According to Fig. 1, the geometry of the slot can transit between a quasi-cross configuration and a rectangular configuration ( $X$-axis dominant or $Y$-axis dominant) depending on the dimensions of the widths and depths of the heads and throats of the fused four T-slots (i.e., $S L_{H}, S L_{V}$, and $S L_{T}$ ).

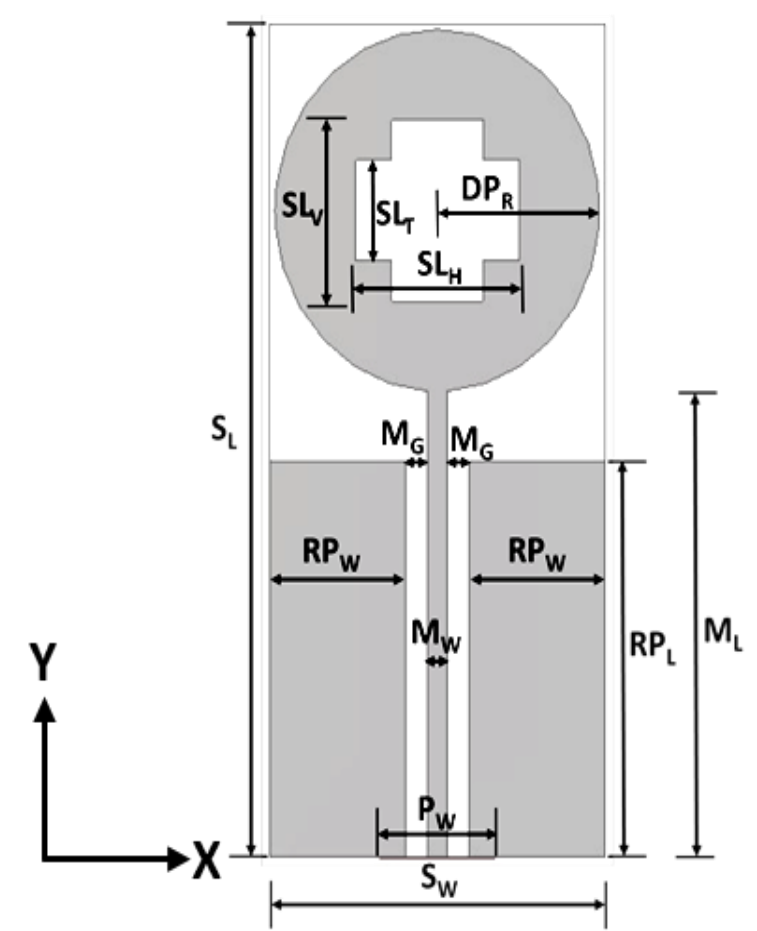

Fig. 1. The layout of the basic/primitive design of the proposed antenna. 
TABLE II

Performance SPECIFICATIONS For The Proposed ANTENNA (UWB SPECTRUM: $3.1 \mathrm{GHZ}$ TO $10.6 \mathrm{GHz}$

\begin{tabular}{lll}
\hline \hline Item & Specification & $\begin{array}{l}\text { PSADEA } \\
\text { Optimum }\end{array}$ \\
\hline Maximum Return loss $\left(\mathrm{S}_{11}\right)$ & $<-10 \mathrm{~dB}$ & $-10.61 \mathrm{~dB}$ \\
Minimum Boresight gain $\left(\mathrm{G}_{\min }\right)$ & $>2 \mathrm{dBi}$ & $2.17 \mathrm{dBi}$ \\
Maximum Boresight gain $\left(\mathrm{G}_{\max }\right)$ & $<5 \mathrm{dBi}$ & $4.74 \mathrm{dBi}$
\end{tabular}

TABLE III

SEARCH RANGES AND DIMENSIONS OF THE PSADEA OPTIMUM FOR THE PROPOSED ANTENNA (ALL SIZES IN $\mathrm{mm}$ )

\begin{tabular}{|c|c|c|c|}
\hline Parameters & $\begin{array}{l}\text { Lower } \\
\text { Bounds }\end{array}$ & $\begin{array}{l}\text { Upper } \\
\text { Bounds }\end{array}$ & $\begin{array}{l}\text { PSADEA } \\
\text { Optimum }\end{array}$ \\
\hline Substrate width $\left(S_{W}\right)$ & $2 \times D P_{R}$ & $3 \times D P_{R}$ & 14.90 \\
\hline Microstrip length $\left(M_{L}\right)$ & $R P_{L}$ & 50.00 & 18.52 \\
\hline Microstrip width $\left(M_{W}\right)$ & 0.50 & 7.50 & 0.84 \\
\hline Microstrip gap $\left(M_{G}\right)$ & $>0.00$ & 21.5 & 0.12 \\
\hline Circular patch radius $\left(D P_{R}\right)$ & 2.00 & 25.00 & 7.21 \\
\hline Width of slot throat $\left(S L_{T}\right)$ & $>0.00$ & $2 \times D P_{R}$ & 5.98 \\
\hline Vertical slots' depth $\left(S L_{V}\right)$ & $>0.00$ & $2 \times D P_{R}$ & 12.06 \\
\hline Horizontal slots' depth $\left(S L_{H}\right)$ & $>0.00$ & $2 \times D P_{R}$ & 5.98 \\
\hline $\begin{array}{l}\text { Partial ground plane length } \\
\left(R P_{L}\right)\end{array}$ & $D P_{R}$ & $M_{L}$ & 18.05 \\
\hline Feed guide width $\left(P_{W}\right)$ & $6 \times M_{W}$ & $10 \times M_{W}$ & 2.56 \\
\hline \multicolumn{4}{|c|}{$\begin{array}{l}\text { Substrate length }\left(S_{L}\right)=M_{L}+\left(2 \times D P_{R}\right)+0.2 \mathrm{~mm} \\
\text { Partial ground plane width }\left(R P_{W}\right)=\left(S_{W}-\left(2 \times M_{G}\right)-M_{W}\right) \div 2\end{array}$} \\
\hline
\end{tabular}

\section{ANTENNA OPTIMIZATION USING PSADEA}

The design of the proposed antenna is challenging mainly due to the large bandwidth requirement and the bore-sight gain specification in the band (Table III). Since the antenna's beam is desired to be broad and flat (i.e., not steered in any particular direction) for easy detection from various angles in a typical microwave imaging setup (Section IV), the antenna's boresight gain has to be within a moderate range over the bandwidth. The design parameters, their geometric constraints and the respective search ranges in Table III are considered for the minimization of the fitness function, $F_{m p a}$ in (1), to satisfy the specifications in Table II. Note that even though the size of the antenna is not included in (1), the search ranges and geometric constraints in Table III are meticulously defined to ensure that the antenna has a low profile. For example, in the optimization process, the microstrip length $\left(M_{L}\right)$ cannot assume values greater than $50 \mathrm{~mm}$ and the partial ground plane length $\left(R P_{L}\right)$ cannot assume values greater than $M_{L}$ according to Table III.

$F_{m p a}=\max \left(S_{11}\right)+w \times \max \left(\left[2 d B i-G_{\text {min }}\right], 0\right)+\cdots$

$w \times \max \left(\left[G_{\max }-5 d B i\right], 0\right)$

where $w$ is the penalty coefficient and it is set to 50. By setting $w$ to be equal to 50, the specifications for the bore-sight gain (i.e., $G_{\min }$ and $G_{\max }$ ) are focused first by largely penalizing $F_{\text {mpa }}$ if they are violated. Then, meeting the $S_{11}$ requirement becomes the primary focus.

Clearly, modern optimization techniques are needed. Trust region framework with empirically determined initial designs and particle swarm optimization in CST-MWS were firstly employed, but they all failed to obtain design solutions which meet the specifications. Then, the PSADEA algorithm is employed.

After 50 hours of optimization, PSADEA obtains the optimal design (with a rectangular slot configuration evolved from the primitive quasi-cross slot configuration in Fig. 1) in Table III with the performance shown in Table II. It can be seen that all the specifications are satisfied. The physical implementation is shown in Fig. 3 and the overall dimension is $33.14 \mathrm{~mm} \times 14.90 \mathrm{~mm} \times 0.84 \mathrm{~mm}$, which corresponds to $0.34 \lambda_{o} \times 0.15 \lambda_{o} \times 0.01 \lambda_{o}$ (where $\lambda_{o}$ is the free space wavelength at $3.1 \mathrm{GHz}$ ). The PSADEA optimized design is more compact than the alternative designs in Table I, which is about half the size (in linear dimensions) of a similar-state-ofthe-art design [25].

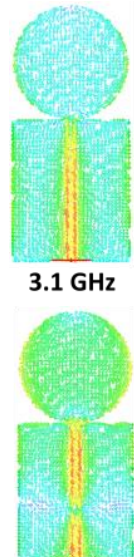

$7.6 \mathrm{GHz}$

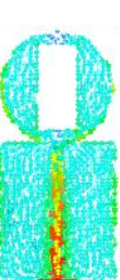

$3.1 \mathrm{GHz}$

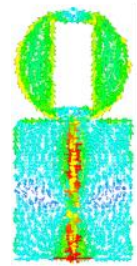

$7.6 \mathrm{GHz}$

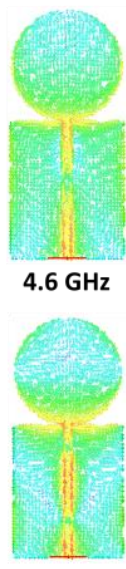

$9.1 \mathrm{GHz}$
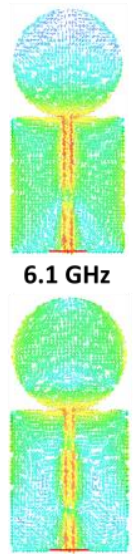

$10.6 \mathrm{GHz}$

(a) Without etching or slot

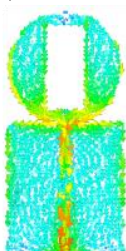

$4.6 \mathrm{GHz}$

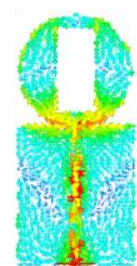

$9.1 \mathrm{GHz}$

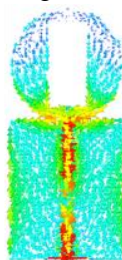

$6.1 \mathrm{GHz}$

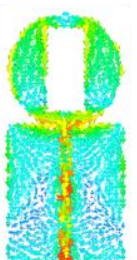

$10.6 \mathrm{GHz}$

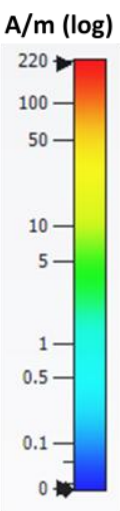

(b) With etching or slot.

Fig. 2. The surface current distribution of the proposed antenna.

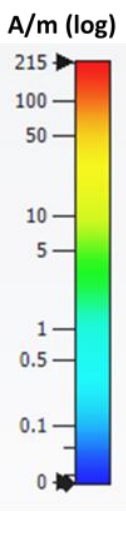

\section{Tests, MEAsurements And Results}

\section{A. Free space reflection coefficient $\left(S_{11}\right)$}

To evaluate the S-parameter performance of the proposed antenna experimentally, a prototype of the antenna was fabricated, as depicted in Fig.3. An Agilent Technologies N5242A vector network analyzer (VNA) was used to compare the simulated and measured reflection coefficient $\left(S_{11}\right)$ in free space, as shown in Fig.3. As can be noticed, both simulated and measured results illustrate that the $S_{11}$ is better than $-10 \mathrm{~dB}$, covering the frequency spectrum from 3 to $11 \mathrm{GHz}$ which is meeting the desired UWB frequency band from 3.1 to 10.6 $\mathrm{GHz}$. Both results are in good agreement up to $10.8 \mathrm{GHz}$, with some differences due to rising around the second resonance which is not as strong and narrow for the experimental measurement as for our simulation. These slight differences in the $S_{11}$ curves can be attributed to the variation of the dielectric constant of the PCB and fabrication inaccuracies. Fig. 4 shows 
the boresight gain versus frequency of the proposed antenna maximum at $4.74 \mathrm{dBi}$ which also indicates the efficiency of the antenna when used for far-field imaging applications.

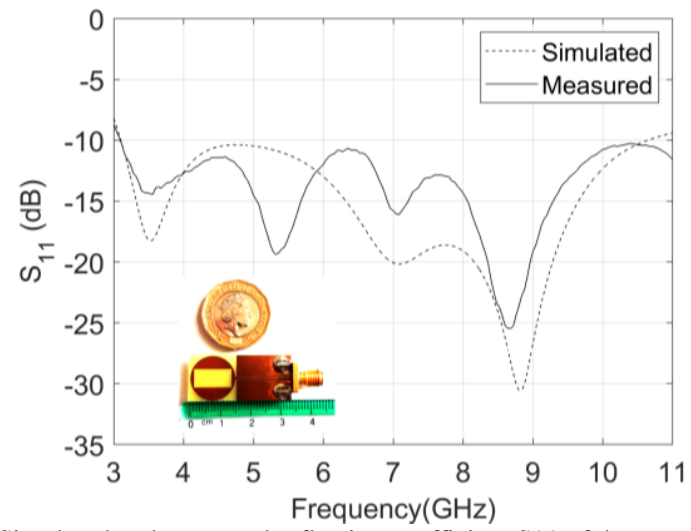

Fig. 3. Simulated and measured reflection coefficient $\mathrm{S} 11$ of the proposed antenna.

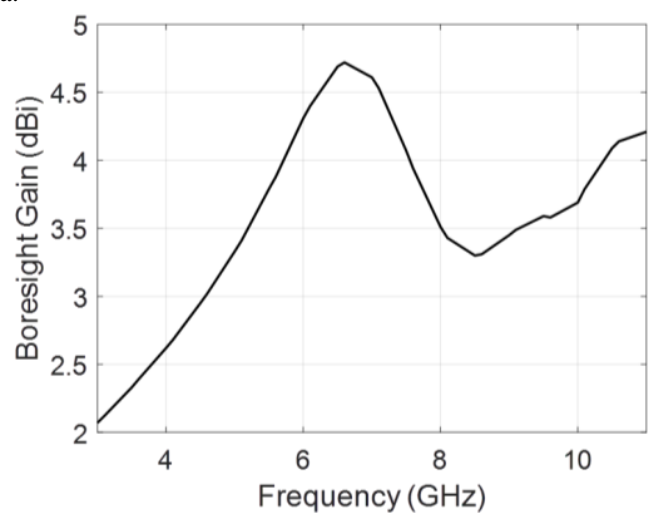

Fig. 4. Simulated boresight gain versus frequency of the proposed antenna.

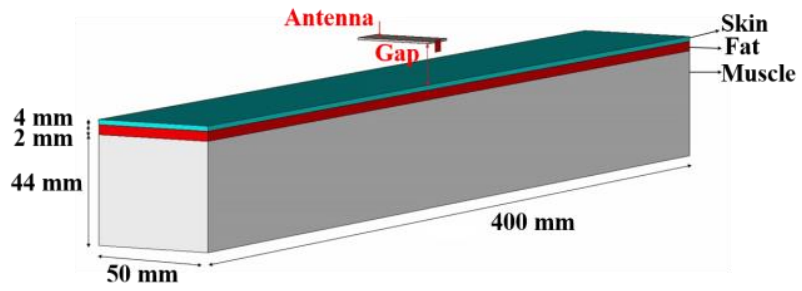

Fig. 5. Proposed antenna with the human arm phantom model.

\section{B. On Body Reflection Coefficient $\left(S_{11}\right)$}

To better understand the antenna performance in close proximity to a human tissue, a three-layer rectangular phantom mimicking the human arm model, and a three layers' cylindrical breast tissue model, were adopted for this study. The arm model composed of a wet skin having dielectric properties of $\left(\varepsilon_{\mathrm{r}}=45.85, \sigma=1.59\right)$, fat $\left(\varepsilon_{\mathrm{r}}=5.28, \sigma=0.1\right)$, and muscle $\left(\varepsilon_{\mathrm{r}}=52.73, \sigma=1.74\right)$, all these are calculated at the lower edge frequency of the UWB spectrum of $3.1 \mathrm{GHz}$ [26], while the breast tissue model uses the same layers except the muscle layer been replaced by the plastic cover layer with $\varepsilon_{\mathrm{r}}=$ 1.7. These values are taken as an average value since these tissue properties are not constant across the whole UWB frequency range. As shown in Fig. 5, the dimension of the human arm model is $50 \mathrm{~mm} \times 50 \mathrm{~mm} \times 400 \mathrm{~mm}$ and it is similar to the model in [27], whereas Fig.5 shows the breast tissue model with a diameter of $120 \mathrm{~mm} x$ length $150 \mathrm{~mm}$. Fig. 7 and Fig. 8 indicate the variations of the $S_{11}$ of the antenna when the distance between the antenna and the human arm and breast tissue models is changed from $0 \mathrm{~mm}$ to $15 \mathrm{~mm}$ with $5 \mathrm{~mm}$ increment. As can be observed, $S_{11}$ curves do not change significantly and it is within the acceptable level (below $-8 \mathrm{~dB}$ ) across the operating band.

The specific absorption rate (SAR) of the antenna was also considered to determine the amount of power that the antenna can transmit within the safety limits. The IEEE C95.1-2005 standard set the SAR average value not to exceed $2 \mathrm{~W} / \mathrm{Kg}$ exceed over $10 \mathrm{~g}$ of human tissue mass [28]. With reference to SAR values, the IEEE limit $(1.6 \mathrm{~W} / \mathrm{kg}$ over $1 \mathrm{~g})$ is exceeded in all the considered situations, while the CENELEC limit of (2 $\mathrm{W} / \mathrm{kg}$ over $10 \mathrm{~g}$ ) is always expected [28, 29]. When the proposed antenna was fed with a $1.3 \mathrm{~W}$ peak input reference power, the SAR distribution averaged over $10 \mathrm{~g}$ of human tissue mass, extended to $15.85 \mathrm{~W} / \mathrm{Kg}$ value at $9.0 \mathrm{GHz}$. In order to satisfy the regulatory requirements of the IEEE C95.1-2005 standard, the delivered power of the antenna was decreased to $135 \mathrm{~mW}$.

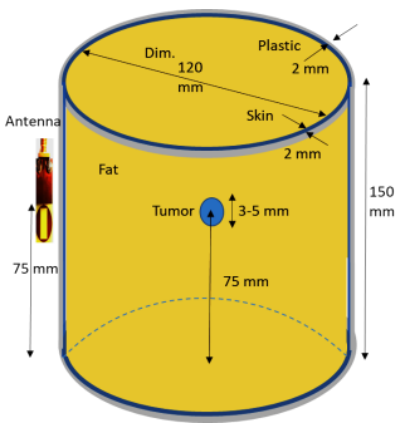

Fig.6. Breast tissue model with the antenna element.

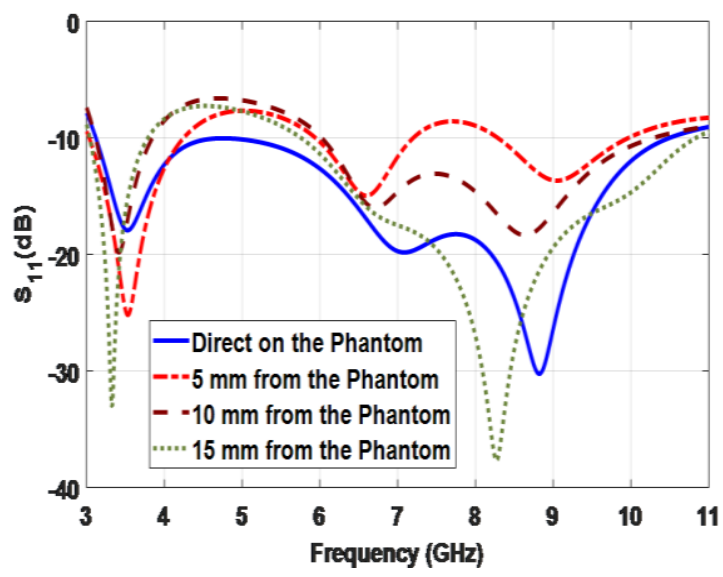

Fig. 7. The $S_{11}$ of the antenna when varying the distance between the antenna and the human arm phantom.

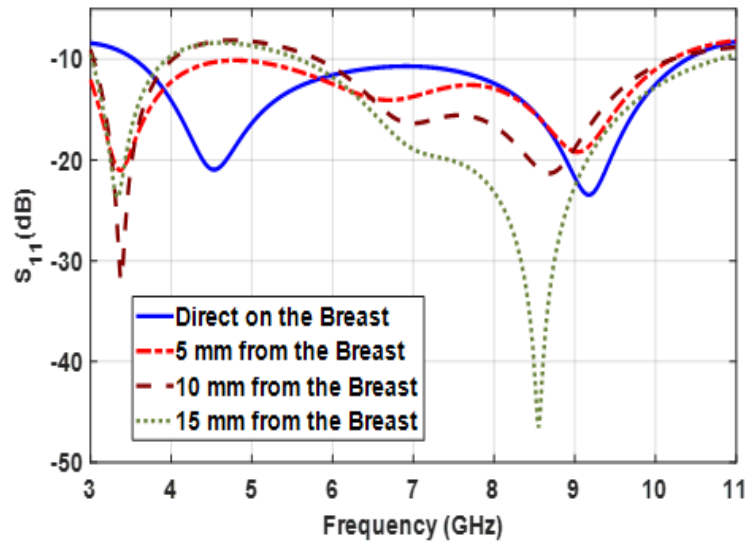

Fig. 8. $\mathrm{S}_{11}$ plots for the antenna placed in close (varying) distances to the breast tissues. 

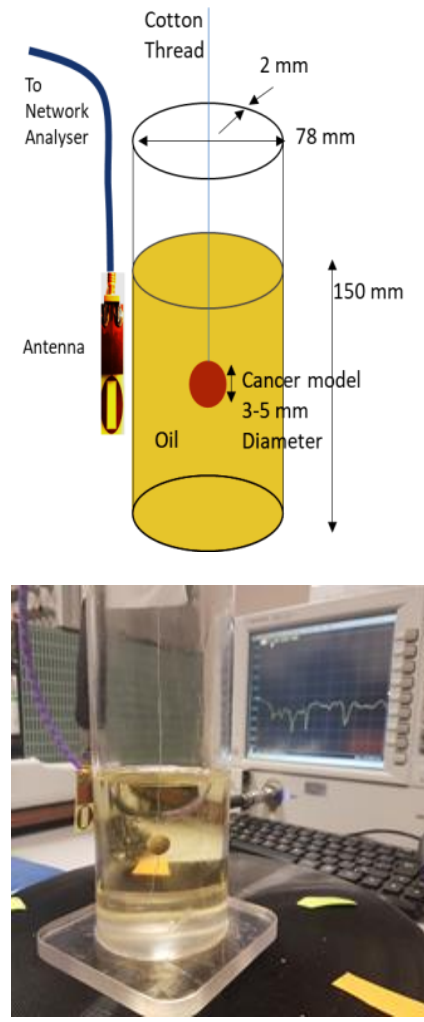

(a) One spherical cancer model (top) prototype (bottom).
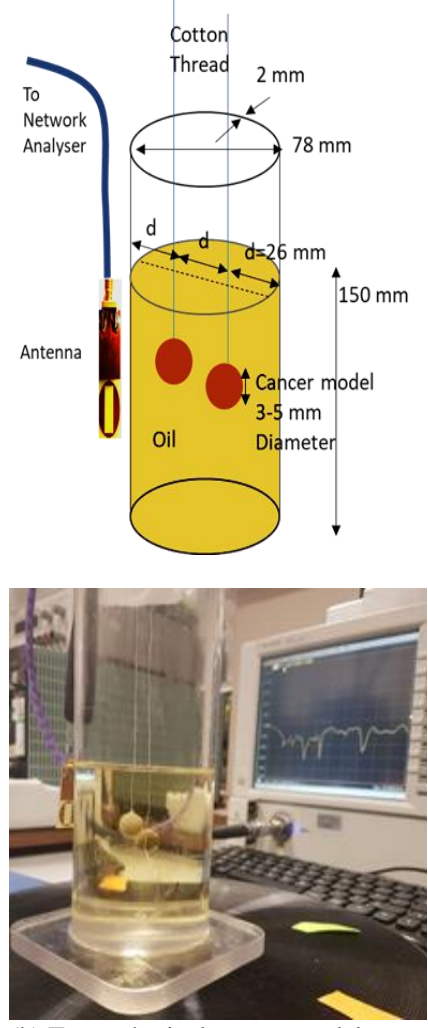

(b) Two spherical cancer model (top), prototype (bottom).

Fig. 9. Proposed antenna placed in close (varying) distances to the breast mimicking phantom.

\section{Antenna Performance in Proximity to Breast Phantom}

In order to practically verify the antenna performance when it is placed in close proximity to a phantom mimicking average breast tissue and tumour based on the recent developments of various medical diagnostic applications of microwave technologies [30], an experiment was carried out as illustrated in Fig.9. The breast mimicking phantom was characterised by electrical properties including conductivity $\sigma=0.4 \mathrm{~S} / \mathrm{m}$ and relative permittivity of $\varepsilon_{r}=9$ and the tumor prepared from scattering material including $10 \mathrm{~g}$ of wheat flour mixed with $5.5 \mathrm{~g}$ of water. The combined mixture has a relative permittivity of 23 with a conductivity of $2.57 \mathrm{~S} / \mathrm{m}$ at a frequency of $4.7 \mathrm{GHz}$ [31]. This mixture is used in this experiment to represent and place inside the breast phantom oil for the experimentation analysis.

The details of the experimental setup are described in Fig. 9. As can be seen, it comprises a circular tube with dimensions of diameter $78 \mathrm{~mm}$, thickness of $2 \mathrm{~mm}$ and height of $150 \mathrm{~mm}$, filled with vegetable oil. The circular tube is mimicking the skin being replaced by a Plexiglas barrier of $2 \mathrm{~mm}$ thickness having dielectric constant varying between 2.39 to 2.59 , with corresponding conductivity of $0.009-0.007 \mathrm{~S} / \mathrm{m}$. The vegetable oil acted as the dielectric filler for safety and cost reasons as it has been used in [3]. The measured $S_{11}$ for the antenna placed on the breast phantom is plotted in Fig. 8 with varying distances from the antenna as illustrated in Fig. 9. Although the properties of the tissue-mimicking phantom are quite different from the simulated phantom or its equivalent tissue, the simulation in Fig. 8 suggests that the antenna is robust to variation in the properties of tissues and maintains its UWB operation.

\section{Breast Cancer Image Reconstruction Algorithm}

Image reconstruction algorithms are used to construct the images after signal processing. A UWB radar-based imaging configuration faces several challenges including antenna design and the image reconstruction of an accurate finite difference time domain-based breast model. Hence, the need to find an effective and efficient image reconstruction algorithm that will provide robust formation, accurate positioning, excellent tumor detection capability and improve computational speed. In this work, promising data-independent algorithms are proposed to provide high-resolution images. These algorithms are delay-multiply-and-sum (DMAS) modified weighted- delay-and-sum (MWDAS) and filtered delay-and-sum (FDAS) [32] as indicated in Figs. 10 to 12.
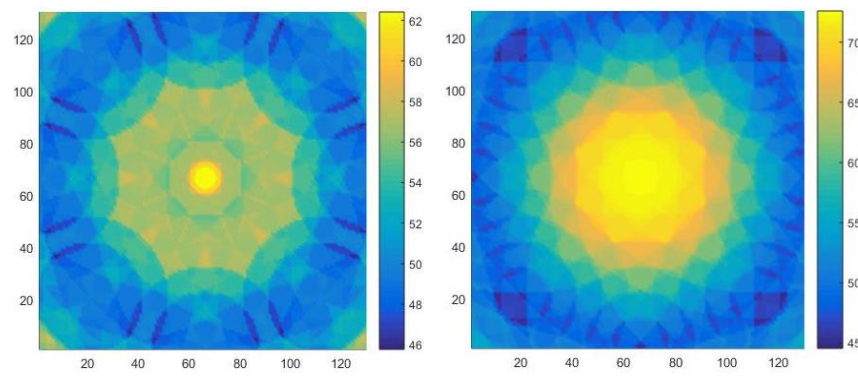

Fig.10. Image reconstruction using DAS (left) and DMAS (right) algorithms with one spherical cancer model shown in Figure 9.

Compared with the classical algorithms, improved performance of clutter rejection is offered by DMAS and DAS. FDAS has the capability of detecting multiple scatters in dense breasts, where the presence of fibro-glandular tissue is considered. It is acknowledged that the increased heterogeneity of normal breasts introduced by glandular tissues constitutes a major setback for tumour detection. There are two reasons affecting this: first, although there is a large dielectric and conductivity contrast between normal and cancerous tissue, the difference between glandular and cancerous tissues is much less pronounced. Also, the glandular tissue introduces a significant amount of attenuation and dispersion in backscattered signals, making it more difficult to detect any small tumours present. These findings showed that the use of the data independent algorithms offered accurate localisation, effective and efficient tumor detection and robust and strong artifact resistance capabilities.
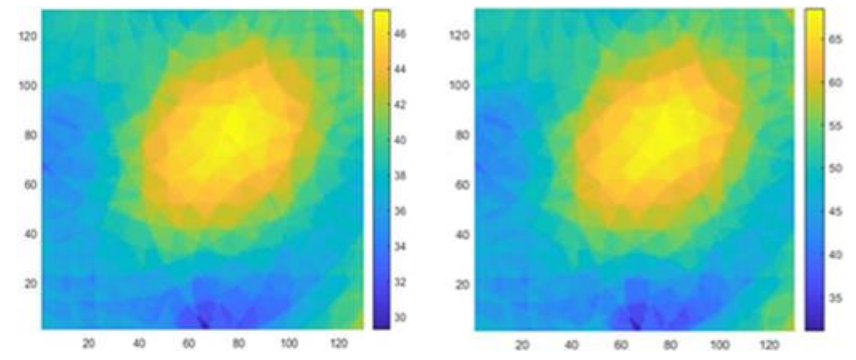

Fig.11. Image reconstruction using DAS (left) and DMAS (right) algorithms with two spherical cancer model shown in Figure 9. 

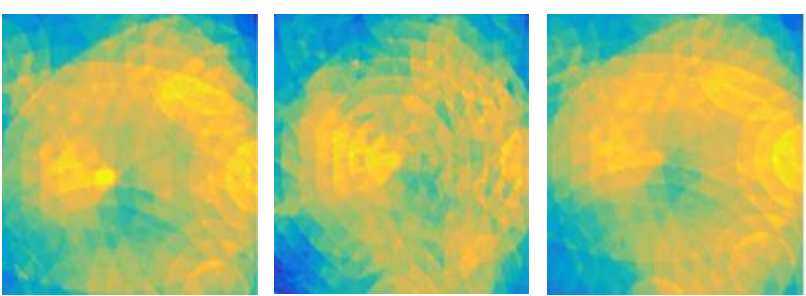

Fig.12. Image reconstruction using DAS (left), DMAS (middle) and FDAS (right) algorithms with three spherical cancer model; spherical models are placed on equal spaced triangular away from the glass surface by $12 \mathrm{~mm}$

\section{CONCLUSIONS}

A rectangular slotted UWB monopole antenna fed with microstrip line and was optimized by the PSADEA algorithm was presented in this paper for body-centric imaging applications. The PSADEA optimized design is more compact than existing similar designs and experimental investigations were carried out using the fabricated prototype, a breast phantom consisting of simulated tumor targets, and a vector network analyzer. The antenna performance was evaluated in both free space and on the body. Experimental results show that the antenna performs well even in close proximity to the phantoms and operationally covers the FCC range of the UWB spectrum. Simulated and measured results demonstrate reasonable agreements. The experimental results suggested that the proposed antenna can be used as a good candidate for UWB breast cancer imaging applications.

\section{REFERENCES}

[1] F. C. Commission, "First report and order regarding ultra wideband transmission system," http://www. fcc. gov, 2002.

[2] J. P. Warhus and J. E. Mast, "Ultra wideband ground penetrating radar imaging of heterogeneous solids,": Google Patents, 1998.

[3] A. F. Mirza, C. H. See, I. M. Danjuma, R. Asif, R. A. Abd-Alhameed, J. M. Noras, et al., "An active microwave sensor for near field imaging," IEEE Sensors Journal, vol. 17, pp. 2749-2757, 2017.

[4] M. M. Rana, R. Khanom, and M. M. Rahman, "Design and Analysis of Vivaldi Antennas," in 2018 International Conference on Innovation in Engineering and Technology (ICIET), 2018, pp. 1-5.

[5] Y. Hao, P. S. Hall, and K. Ito, "IEEE Transactions on Antennas and Propagation Announces Special Issue on Antennas and Propagation for Body-Centric Wireless Communications," IEEE Antennas and Propagation Magazine, vol. 49, pp. 201-201, 2007.

[6] P. S. Hall and Y. Hao, "Antennas and propagation for body centric communications," in 2006 First European Conference on Antennas and Propagation, 2006, pp. 1-7.

[7] D. M. Pozar, Microwave Engineering 3e: Wiley, 2006.

[8] S. H. Choi, J. K. Park, S. K. Kim, and J. Y. Park, "A new ultra-wideband antenna for UWB applications," Microwave and optical technology letters, vol. 40, pp. 399-401, 2004.

[9] P. S. Hall, "Antennas challenges for body centric communications," in 2007 International workshop on Antenna Technology: Small and Smart Antennas Metamaterials and Applications, 2007, pp. 41-44.

[10] C. A. Balanis, Antenna theory: analysis and design: John Wiley \& Sons, 2016.

[11] C. Baytöre, M. C. Özgönül, M. Palandöken, B. Özbakış, and A. Kaya, "Low cost dual band monopole antenna design and analysis for 802.11 b/g/n/ac standards," in 2015 23nd Signal Processing and Communications Applications Conference (SIU), 2015, pp. 2070-2073.

[12] I. M. Danjuma, M. O. Akinsolu, G. Oguntala, A. Asahraa, R. A. AbdAlhameed, M. Bin-Melha, et al., "AT slot monopole antenna for UWB microwave imaging applications, Loughborough Antennas \& Propagation Conference, 12-13 Nov. 2018, pp. 1-5, 2018.

[13] S. V. P. Rao and A. Sudhakar, "A compact OCTAGONAL printed monopole UWB antenna for bio-medical applications," in 2015 13th International Conference on Electromagnetic Interference and Compatibility (INCEMIC), 2015, pp. 131-134.

[14] A. R. Celik and M. B. Kurt, "Development of an ultra-wideband, stable and high-directive monopole disc antenna for radar-based microwave imaging of breast cancer," Journal of Microwave Power and Electromagnetic Energy, vol. 52, pp. 75-93, 2018.

[15] R. Kumar and N. Kushwaha, "Design and investigation of sectoral circular disc monopole fractal antenna and its backscattering," Engineering Science and Technology, an International Journal, vol. 20, pp. 18-27, 2017.

[16] B. Liu, M. O. Akinsolu, N. Ali, and R. Abd-Alhameed, "Efficient global optimisation of microwave antennas based on a parallel surrogate modelassisted evolutionary algorithm," IET Microwaves, Antennas \& Propagation, vol. 13, pp. 149-155, 2018.

[17] B. Liu, S. Koziel, and N. Ali, "SADEA-II: A generalized method for efficient global optimization of antenna design," Journal of Computational Design and Engineering, vol. 4, pp. 86-97, 2017.

[18] M. O. Akinsolu, B. Liu, V. Grout, P. I. Lazaridis, M. E. Mognaschi, and P. Di Barba, "A parallel surrogate model assisted evolutionary algorithm for electromagnetic design optimization," IEEE Transactions on Emerging Topics in Computational Intelligence, vol. 3, pp. 93-105, 2019

[19] B. Liu, M. O. Akinsolu, N. Ali, and R. Abd-Alhameed, "Efficient global optimisation of microwave antennas based on a parallel surrogate modelassisted evolutionary algorithm," IET Microwaves, Antennas \& Propagation, vol. 2, Issue 2, pp.149-155, 2018.

[20] M. O. Akinsolu, I. M. Danjuma, K. K. Mistry, B. Liu, R. A. AbdAlhameed, P. I. Lazaridis, et al., "Efficient AI-Driven Design of Microwave Antennas Using PSADEA," in 2019 2nd IEEE Middle East and North Africa Communications' Conference (MENACOMM), 2019, pp. 1-5.

[21] V. Grout, M. O. Akinsolu, B. Liu, P. I. Lazaridis, K. K. Mistry, and Z. D. Zaharis, "Software Solutions for Antenna Design Exploration: A Comparison of Packages, Tools, Techniques, and Algorithms for Various Design Challenges," IEEE Antennas and Propagation Magazine, vol. 61 , pp. $48-59,2019$.

[22] Q. Hua, Y. Huang, C. Song, M. O. Akinsolu, B. Liu, T. Jia, et al., "A Novel Compact Quadruple-Band Indoor Base Station Antenna for 2G/3G/4G/5G Systems," IEEE Access, vol. 7, pp. 151350-151358, 2019.

[23] B. Liu, Q. Zhang, and G. G. Gielen, "A Gaussian process surrogate model assisted evolutionary algorithm for medium scale expensive optimization problems," IEEE Transactions on Evolutionary Computation, vol. 18 , pp. 180-192, 2013

[24] H.-W. Liu, C.-H. Ku, T.-S. Wang, and C.-F. Yang, "Compact monopole antenna with band-notched characteristic for UWB applications," IEEE Antennas and Wireless Propagation Letters, vol. 9, pp. 397-400, 2010.

[25] B. Yeboah-Akowuah, P. Kosmas, and Y. Chen, "A Q-slot monopole for UWB body-centric wireless communications," IEEE Transactions on Antennas and Propagation, vol. 65, pp. 5069-5075, 2017.

[26] C. Gabriel, "Dielectric properties of biological materials," in Bioengineering and Biophysical Aspects of Electromagnetic Fields, ed: CRC press, 2006, pp. 86-135.

[27] C.-H. Lin, K. Saito, M. Takahashi, and K. Ito, "A compact planar Inverted-F antenna for $2.45 \mathrm{GHz}$ on-body communications," IEEE transactions on antennas and propagation, vol. 60, pp. 4422-4426, 2012.

[28] R. A. Abd-Alhameed, P. S. Excell, and M. A. Mangoud, "Computation of specific absorption rate in the human body due to base-station antennas using a hybrid formulation," IEEE Transactions on Electromagnetic Compatibility, vol. 47, pp. 374-381, 2005.

[29] R. A. Abd-Alhameed, P. S. Excell, and M. A. Mangoud, "A hybrid computational electromagnetics formulation for simulation of antennas coupled to lossy and dielectric volumes," IEEE transactions on broadcasting, vol. 50, pp. 253-259, 2004

[30] Y. Chen, P. Kosmas, and S. Martel, "A feasibility study for microwave breast cancer detection using contrast-agent-loaded bacterial microbes," International Journal of Antennas and Propagation, vol. 2013, 2013

[31] S. A. AlShehri, S. Khatun, A. B. Jantan, R. S. A. Raja Abdullah, R. Mahmud, and Z. Awang, "Experimental breast tumor detection using NN-based UWB imaging," Progress in Electromagnetics Research, vol 111, pp. 447-465, 2011

[32] T. Yin, F. H. Ali, and C. C. Reyes-Aldasoro, "A robust and artifact resistant algorithm of ultra wideband imaging system for breast cancer detection," IEEE Transactions on Biomedical Engineering, vol. 62, pp. 1514-1525, 2015.

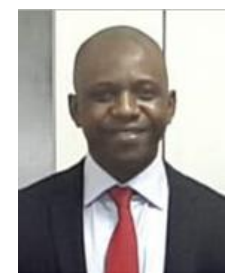

ISAH MUSA DANJUMA (M'17) received the B.Eng. degree in Electrical and Electronic Engineering from Bayero University Kano and M. Tech in Electronic and Telecommunications Engineering from Obafemi Awolowo University, Ile-Ife, Nigeria in 2000 and 2007 , respectively. From 2016 to 2019, he was a Ph.D scholarship awardee sponsored by Tertiary Education Trust Fund (TETFund) of Nigeria. He is currently a research assistant at the Antennas and Applied Electromagnetics Research Group of the Faculty of Engineering and 
Informatics, University of Bradford. Mr. Danjuma is a member of the Institution of Electrical and Electronics Engineering, Institution of Electrical Technology and also a registered member of the Nigerian Society of Engineers. His research interests cover wireless sensor network system design, computational electromagnetism, antennas and acoustic sensor design. He has published many journal articles and conference papers in the areas of antennas, computational electromagnetics and wireless sensor system designs.

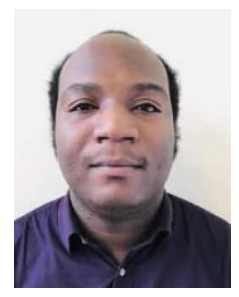

Mobayode O. Akinsolu (M'16) received the M.Sc. with Distinction in electrical and electronic engineering from the University of Bradford, UK in 2014 after his undergraduate studies and compulsory national service in Nigeria. He then worked as a research fellow (industrial attaché) and a visiting researcher at the National Space Research and Development Agency, Nigeria and the RFID Research Centre, African University of Science and Technology, Nigeria, respectively until 2016. From 2016 to 2019, he was a Ph.D. scholarship awardee in recognition of a joint project between Wrexham Glyndŵr University, UK and the University of Birmingham, UK. His Ph.D. research focused on electromagnetic design automation using surrogate model-assisted evolutionary algorithms. He is currently a lecturer in electronic and communication engineering at Wrexham Glyndŵr University, UK. He is a member of the IET and a registered electrical engineer with the COREN.

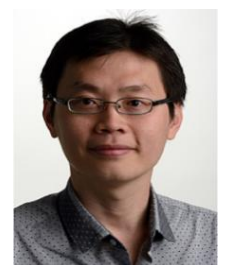

CHAN HWANG. SEE (M'14, SM'15) received a first class B.Eng. Honours degree in Electronic Telecommunication and Computer Engineering and a Ph.D. degree from the University of Bradford, UK in 2002 and 2007, respectively. He is an associate Professor and Head of Electrical Engineering and Mathematics in School of Engineering and the Built Environment, Edinburgh Napier University, UK. Previously, he is a Senior Lecturer (Programme Leader) in Electrical \& Electronic Engineering, School of Engineering, University of Bolton, UK. He also is a Visiting Research Fellow in School of Engineering and Informatics, University of Bradford, UK. Prior to this, he was a Senior Research Fellow in the Antennas and Applied Electromagnetics Research Group within the University of Bradford. His research interests cover wireless sensor network system design, computational electromagnetism, antennas and acoustic sensor design. He has published over 200 peer-reviewed journal articles and conference papers in the areas of antennas, computational electromagnetics, microwave circuits and wireless sensor system designs. He is a co-author for one book and three book chapters. He was a recipient of two Young Scientist Awards from the International Union of Radio Science (URSI) and Asia-Pacific Radio Science Conference (AP-RASC) in 2008 and 2010, respectively. He was awarded a certificate of excellence for his successful Knowledge Transfer Partnership (KTP) with Yorkshire Water on the design and implementation of a wireless sensor system for sewerage infrastructure monitoring in 2009. Dr. See is a Chartered Engineer, Fellow of the Institution of Engineering and Technology. $\mathrm{He}$ is also a Fellow of the Higher Education Academy and Associate Editor for IEEE Access.

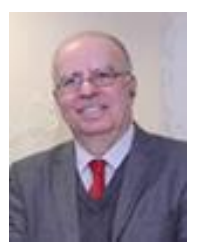

RAED A. ABD-ALHAMEED ( M'02, SM'13) is currently a Professor of electromagnetic and radiofrequency engineering with the University of Bradford, U.K. He is also the Leader of radiofrequency, propagation,sensor design, and signal processing; in addition to leading the Communications Research Group for years within the School of Engineering and Informatics, University of Bradford. He has long years' research experience in the areas of radio frequency, signal processing, propagations, antennas, and electromagnetic computational techniques. He has published over 600 academic journals and conference papers; in addition, he has co-authored five books and several book chapters. He is a principal investigator for several funded applications to EPSRCs and the leader of several successful knowledge Transfer Programmes, such as with Arris (previously known as Pace plc), Yorkshire Water plc, Harvard Engineering plc, IETG Ltd., Seven Technologies Group, Emkay Ltd., and Two World Ltd. He has also been a coinvestigator in several funded research projects including 1) Horizon 2020 Research and Innovation programme under grant agreement H2020-MSCARISE-2019-eBORDER-872878; 2) H2020 MARIE Sk odowska-CURIE ACTIONS: Innovative Training Networks Secure Network Coding for Next Generation Mobile Small Cells 5G-US; 3) Nonlinear and demodulation mechanisms in biological tissue (Dept. of Health, Mobile Telecommunications \& Health Research Programme; and 4) Assessment of the Potential Direct Effects of Cellular Phones on the Nervous System (EU: collaboration with six other major research organizations across Europe). He was a recipient of the
Business Innovation Award for his successful KTP with Pace and Datong companies on the design and implementation of MIMO sensor systems and antenna array design for service localizations. He is the chair of several successful workshops on energy-efficient and reconfigurable transceivers: Approach toward Energy Conservation and CO2 Reduction that addresses the biggest challenges for the future wireless systems. $\mathrm{He}$ is a co-editor for Electronics MDPI Journal since June 2019; in addition, he was a Guest Editor of IET Science, Measurements and Technology Journal since 2009. He has been a Research Visitor of Wrexham University, Wales, since 2009, covering the wireless and communications research areas. His interest in computational methods and optimizations, wireless and mobile communications, sensor design, EMC, beam steering antennas, energy-efficient PAs, and RF predistorter design applications. He is a fellow of the Institution of Engineering and Technology and a fellow of the Higher Education Academy and Chartered Engineer.

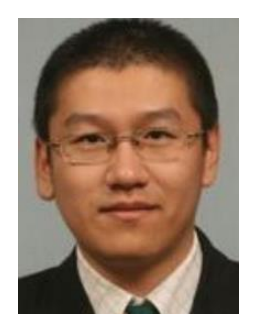

Bo Liu (M'15-SM'17) received the B.Eng. degree from Tsinghua University, P. R. China, in 2008. He received his Ph.D. degree at University of Leuven (KU Leuven), Belgium, in 2012. From 2012 to 2013, he was a Humboldt research fellow and was working with Technical University of Dortmund, Germany. In 2013, he was appointed Lecturer (Assistant Professor) at Wrexham Glyndwr University, UK, where he was promoted to Reader (Associate Professor) in 2016. Since 2020, he is a Senior Lecturer (Associate Professor) at University of Glasgow, UK. His research interests lie in AIdriven design methodologies of analog/RF integrated circuits, microwave devices, MEMS, evolutionary computation and machine learning. He has authored or co-authored 1 book and more than 60 papers in renowned international journals, edited books and conference proceedings. 